\title{
INTERPLAY BETWEEN STEMNESS AND INFLAMMATORY MODULATORS IN ORAL EPITHELIAL DYSPLASIA
}

\author{
Shaimaa Eliwa Ghazy* and Nermeen S. Afifi*
}

\begin{abstract}
Review: The backbone of clonal evolution model claims that every individual malignant cell has the potential to initiate a new neoplasm. Yet, the cancer stem cell theory confirms that only a few number of stem-like cancer cells can initiate a new neoplasm with all clones of the original neoplasm. CD133 is the most commonly used marker to identify the CSCs from different malignancies. Among the important mediators of the inflammatory pathways is COX-2, which has been found to be elevated in several human cancers. The strong association of different types of cancer with some chronic inflammatory diseases confirms the influential role of inflammation in carcinogenesis.
\end{abstract}

Aim of study: The present study aimed to find the possible correlation between the stemness $(\mathrm{CD} 133+)$ and the inflammatory modulator (COX-2) in different grades of oral epithelial dysplasias which might help in predicting the oral cancer development.

Material and Methods: Immunohistochemical expression of CD133 and COX-2 was evaluated in 5 histologically normal samples of normal oral mucosa and 30 samples of oral dysplasia.

Results: For both CD133 and COX-2, there were a statistically significant difference between the different grades of oral dysplasias (P-value $<0.001$, Effect size $=0.956$ for CD133 and 0.942 for COX-2).

Conclusion: The gradual over expression of CD133 and COX-2 from normal to different grades of oral dysplastic lesions suggests the potential role of these both proteins in oral carcinogenesis, and might help in the diagnosis and the prediction of the oral cancer development.

KEY WARDS: Cancer stem cells, CD133, COX-2, Oral dysplasia

* Lecturer of Oral Pathology, Faculty of Dentistry, Ain Shams University 


\section{INTRODUCTION}

The way by which cancer occurs still a mysterious issue regardless all the improvements in cancer research. Nowadays the cancer stem cell (CSC) postulate is strengthened, challenging the theory of 'clonal evolution' for malignant occurrence and implying the emergence of a possible treatment for malignant neoplasms ${ }^{[1]}$.

The backbone of clonal evolution model claims that every individual malignant cell has the potential to initiate a new neoplasm ${ }^{[2]}$. Yet, the cancer stem cell theory confirms that only a few number of stem-like cancer cells can initiate a new neoplasm with all clones of the original neoplasm, while the rest of the malignant cells have restricted power of proliferation ${ }^{[3]}$. The novel recognition of precancerous stem cells (pCSCs) emphasizes that the "clonal evolution" is not paradoxical to the CSC hypothesis, but considered as an aspect of the procedure of CSC up growth ${ }^{[4]}$.

The malignant stem cell exploration is still in its beginning, many questions concerning the role of pCSC cannot be answered nowadays. Development of cancer comprises a reversible pre-cancerous phase. However the mechanism of all cancer events still under research ${ }^{[5]}$.

Different researchers have specified biomarkers on the surface of CSCs to set them a part from the rest of the tumor cells. CD133 is the most commonly used marker to identify CSCs from different malignancies ${ }^{[6]}$. CD133 is a $120 \mathrm{KDa}$, pentaspan transmembrane glycoprotein which was observed in hematopoietic stem cells. Recently the increase of CD133 expression was detected in oral cancer stem-like cells and its gradual overexpression from normal mucosa to dysplasia then carcinoma was reported $^{[7]}$.

Among the other stem cell markers Oct-, and CD117 ${ }^{[8]}$. CD133 was found to be an important indicator of the future of colorectal, lung and brain tumors ${ }^{[9-11]}$. Amusingly, CD133 expression decreases during cell differentiation and the laryngeal carcinoma cell line with high CD133 expression display a stem cell features such as selfrenewal ${ }^{[12,13]}$. The tongue squamous cell carcinoma with positive CD133 expression exhibits resistance to chemotherapy ${ }^{[14,15]}$.

There is a strong relation between inflammation and malignant tumors. Production of inflammatory mediators creates a suitable environment for cancer appearance $^{[16,17]}$.

The strong association of different types of cancer with some chronic inflammatory diseases confirms the influential role of inflammation in carcinogenesis. Colon cancer risk is strongly related to inflammatory bowel diseases, like ulcerative colitis disease. Moreover, some anti-inflammatory drugs not only reduces the cancer occurrence but also decreases recurrence and metastasis ${ }^{[18]}$.

Among the important mediators of the inflammatory pathways is COX-2, which has been found to be elevated in several human cancers. The other inflammatory mediators involved in cancer occurrence, prostaglandins, thromboxanes and leukotrienes. Expression of prostaglandins is controlled by the activity of Cyclooxygenase family $(\mathrm{COX})^{[19,20,21]}$.

COX-2 is stimulated by different stimuli, such as lipopolysaccharide (LPS), interleukin-1 (IL1), tumor necrosis factor (TNF) and epidermal growth factor (EGF) $)^{[22,23]}$. The production of COX-2 is linked to many events involved in cancer such as apoptosis resistance, uncontrolled cell growth, invasion and new blood vessels formation. prostaglandins produced by COX-2 act as immunosuppressors by decreasing the macrophage and natural killer cell mediated cytotoxicity ${ }^{[21,24]}$.

Inflammation and cancer stem cells (CSCs) have been reported to have a strong role in breast cancer $^{[25]}$. But to our knowledge this correlation has not been sufficiently studied in oral cancer development, so in this study, we aimed to find 
the possible correlation between the stemness (CD133+) and the inflammatory modulator (COX2) in different grades of oral epithelial dysplasias which might help in predicting the oral cancer development.

\section{MATERIALS AND METHODS}

The cases used in this study consisted of 5 histologically normal samples of normal oral mucosa and 30 samples of oral dysplasia: 10 samples with mild epithelial dysplasia, 10 samples with moderate epithelial dysplasia and 10 samples with severe epithelial dysplasia. All cases were obtained from the archive of Oral Pathology Department, Faculty of Dentistry, Ain Shams University. Briefly, immunohistochemical staining was performed as follows: sections were deparaffinized using xylene and rehydrated in graded alcohol. Sections were applied in citrate buffer before the staining procedures. The universal kit (Lab Vision, USA) was used. Peroxidase-antiperoxidase procedure using the biotin-streptavidin system was done, $3 \%$ hydrogen peroxide was added to the section to stop the endogenous peroxidase action. The sections were immunolabelled using the primary antibodies CD133 and COX-2 (Lab Vision, Fermont CA, USA) and then incubated overnight at room temperature. Sections were washed with phosphate buffer saline (PBS) then covered by the link antibody.Then the streptavidin labeling antibody was added. After rinsing with PBS, diaminobenzidine chromogen was added to the sections and then the counterstain was added. Sections were dehydrated in a graded alcohol, then in xylene and finally mounted. All the steps for immunohistochemical quantitative evaluation were done on photomicrographs captured at a magnification of $\mathrm{X} 40$ using image analysis software (Image J, 1.41a, NIH, USA).

Data were checked for normality by checking the distribution of data and using tests of normality (Kolmogorov-Smirnov and Shapiro-Wilk tests). Results showed normal (parametric) distribution. Results were presented as mean, standard deviation
(SD) and 95\% Confidence Interval (95\% CI) values. One-way ANOVA test was done to compare inbetween the different grades of oral dysplasias for each marker. Bonferroni's post-hoc test was used for pair-wise comparisons. Pearson's correlation coefficient was used to determine the correlation between CD133 and COX-2. The significance level was set at $\mathrm{P} \leq 0.05$. Statistical analysis was performed with using the Statistical Package for Social Science (SPSS 15.0) Software.

\section{RESULTS}

\section{Immunohistochemical Results}

CD133: All the 30 cases (100\%) of various grades of oral dysplasia examined in this study showed CD133 immunopositivity, while the immunohistochemical analysis of normal oral mucosa did not show any immunoreactivity (fig.1A).

In mild dysplasia, the expression was mainly localized to the cytoplasm of the basal cells while the suprabasal layers showed nuclear reaction in some cells (fig.lB). In moderate dysplasia, more expression was observed and extended to the middle one third of the surface epithelium, the reaction was mainly cytoplasmic and membranous but some cells showed a nuclear reaction (fig.lC). Concerning severe dysplasia, the expression was observed in the whole layers of epithelium, mainly with cytoplasmic expression and few cells showed a nuclear reaction (fig.1D). CD133 immunopositivity was also noted in some stromal cells in nearly all cases of oral dysplasia.

COX-2: All the 30 cases (100\%) of different grades of oral dysplasias, tested in this study revealed COX-2 immunopositivity. Immunohistochemical results of normal oral mucosa did not reveal COX-2 immunopositivity (fig.lE).

In mild dysplasia, the immunopositive cells are scattered among the basal and suprabasal cells exhibiting mainly cytoplasmic reaction with few cells showing nuclear reaction. A few 
scattered immunopositive cells were revealed among the superficial layers of the epithelium (fig. $1 F)$. In moderate dysplasia, cytoplasmic COX2 immunoexpresion was extended to cover the lower third of epithelium with many scattered immunopositive cells among the other layers of the epithelium. The perinuclear reaction were intense
(fig.lG). In severe dysplasia, nearly all the layers of the epithelium showed immunopositivity for COX2 protein. The localization was cytoplasmic as well as perinuclear (figs.lH). COX-2 immunopositivity was also noted in some stromal cells in nearly all cases of oral dysplasia.

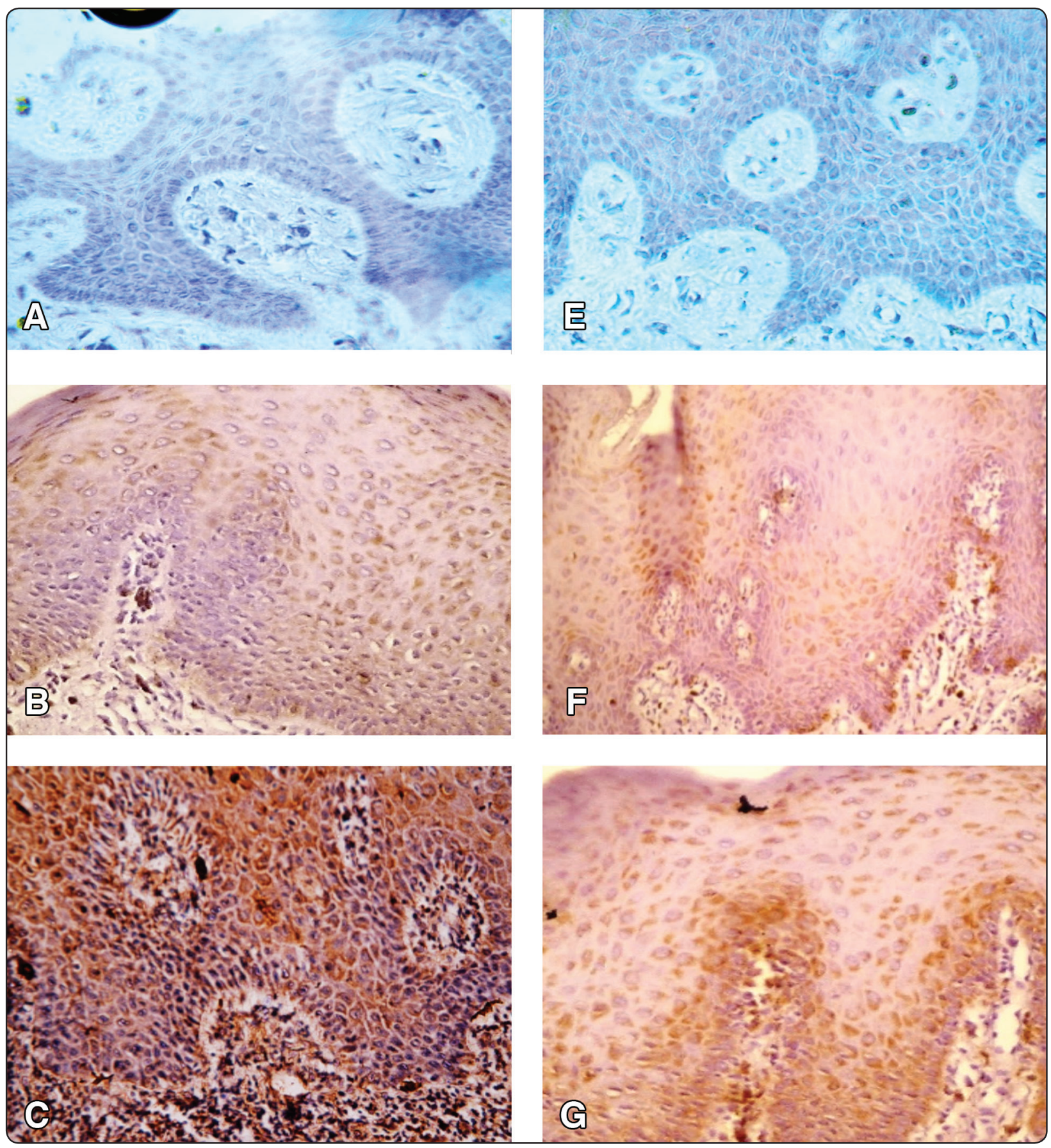




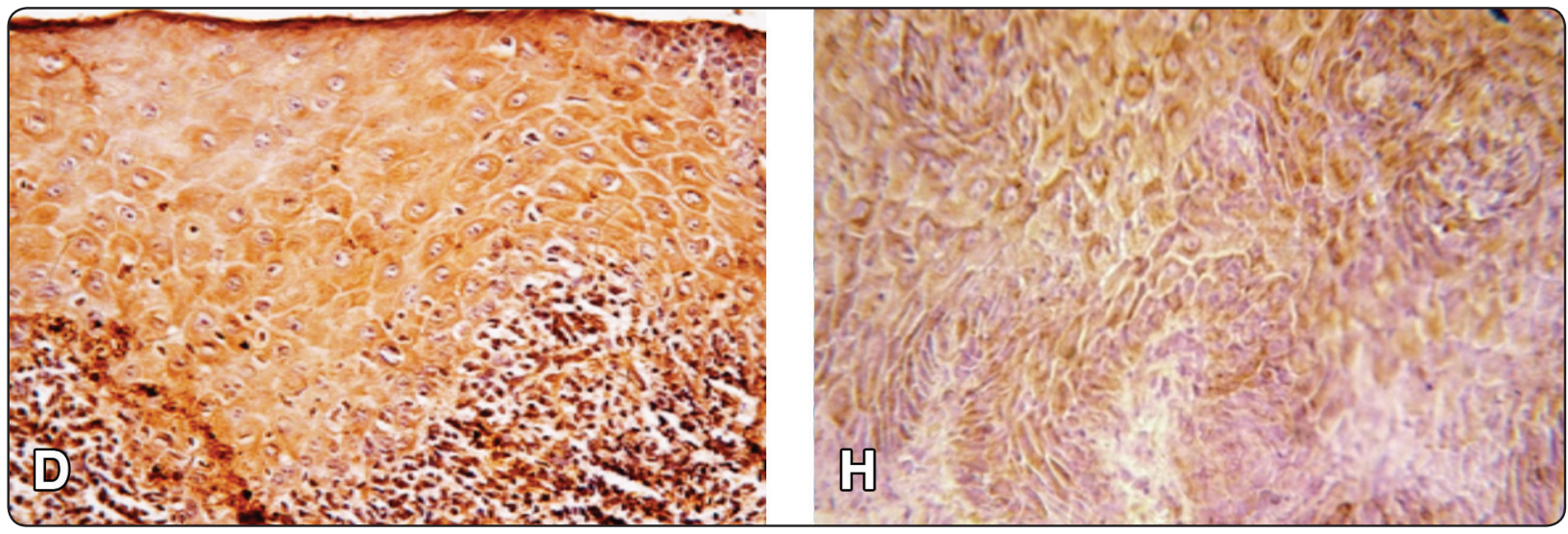

Fig. (1) Photomicrographs of immunohistochemical results of CD133 and COX-2 in normal oral mucosa and different grades of oral dysplasia. A, B, C, D: CD133 in normal mucosa, mild, moderate and severe dysplasia respectively, while E, F, G, H: COX-2 in normal mucosa, mild, moderate and severe dysplasia respectively (Orig. Mag. X40).

\section{2- Statistical results:}

For both CD133 and COX-2, there were a statistically significant difference between the different grades of oral dysplasias ( $\mathrm{P}$-value $<0.001$, Effect size $=0.956$ for CD133 and 0.942 for COX2) (table 1 and fig. 2). Bonferroni's post-hoc test for Pair-wise comparisons between different grades of oral dysplasias for both CD133 and COX-2 revealed that severe dysplasia group showed the statistically significantly highest mean percent. Moderate dysplasia group showed statistically significantly lower mean percent. Mild dysplasia group showed the statistically significantly lowest mean percent (table 1, fig.2).

\section{Correlation between COX-2 and CD133}

There was a statistically significant direct (positive) correlation between COX-2 and CD133 $(\mathrm{r}=0.956$, P-value $<0.001)$. An increase in COX2 percent is associated with an increase in CD133 percent and vice versa (fig. 3 ).

TABLE (1): Mean, standard deviation and one-way ANOVA test for comparisons between the different grades of oral dysplasias with CD133 and COX-2

\begin{tabular}{|c|c|c|c|c|c|c|}
\hline \multicolumn{2}{|c|}{} & $\begin{array}{c}\text { Mild dysplasia } \\
(\mathbf{n = 1 0})\end{array}$ & $\begin{array}{c}\text { Moderate dysplasia } \\
(\mathbf{n = 1 0})\end{array}$ & $\begin{array}{c}\text { Severe dysplasia } \\
(\mathbf{n = 1 0})\end{array}$ & P-value & $\begin{array}{c}\text { Effect size } \\
(\text { Eta } \text { squared })\end{array}$ \\
\hline \multirow{2}{*}{ CD133 } & Mean (SD) & $17.3(1.6)^{\mathrm{C}}$ & $41.2(2.3)^{\mathrm{B}}$ & $62.8(6.7)^{\mathrm{A}}$ & & \multirow{2}{*}{0.956} \\
\cline { 2 - 6 } & $\mathbf{9 5 \%}$ CI & $16.2-18.5$ & $39.5-42.8$ & $58-67.6$ & $<0.001^{*}$ & \multirow{2}{*}{0.942} \\
\hline \multirow{2}{*}{ COX-2 } & Mean (SD) & $15.4(3)^{\mathrm{C}}$ & $28.3(3)^{\mathrm{B}}$ & $42.8(2.7)^{\mathrm{A}}$ & & \multirow{2}{*}{} \\
\cline { 2 - 6 } & $\mathbf{9 5 \%}$ CI & $13.3-17.6$ & $24.6-35.6$ & $40.8-44.7$ & $<0.001^{*}$ & \\
\hline
\end{tabular}

* Significant at $P \leq 0.05$, Different superscripts in the same row are statistically significantly different 


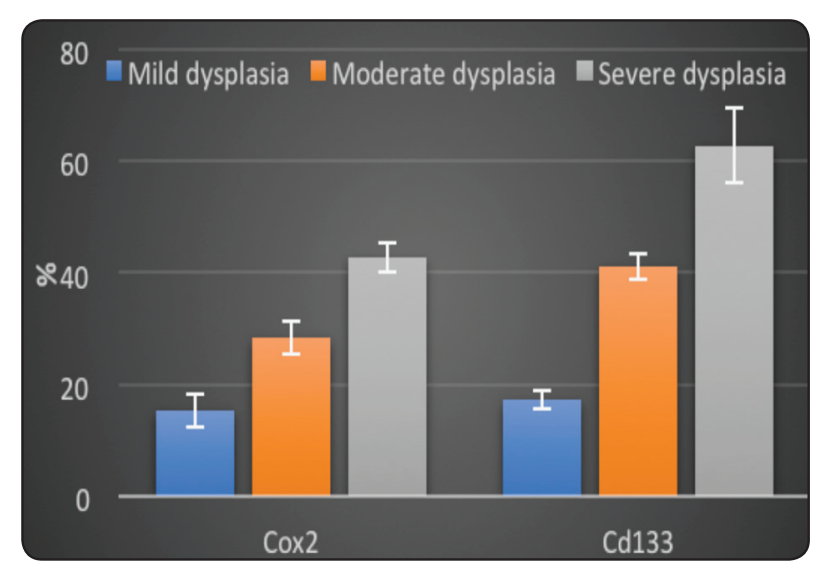

Fig. (2): column chart representing mean and standard deviation values for CD133 and COX-2 in the different grades of oral dysplasias.

\section{DISCUSSION}

Oral squamous cell carcinoma (OSCC) is the mostly occurring neoplasm in the head and neck area accompanied with high death rates ${ }^{[26]}$.

The relation between inflammation and cancer stem cells (CSCs) has a known strong effect in breast cancer ${ }^{[25]}$. In the present research, we have examined the expression pattern of CD133 and one of the inflammatory modulators; COX-2 in oral epithelial dysplasias of different grades. We also explored the relation between the presence of both molecular markers.

In this study, CD133 was highly expressed in the different grades of oral epithelial dysplasias in comparison to the normal oral epithelium, which revealed a negative staining of CD133. A gradual increase in the expression was detected where the mild dysplastic group showed a statistically significant lowest mean percent while the severe dysplastic group showed a statistically significant highest mean percent followed by the moderately dysplastic group. This findings was in accordance with previous studies which suggest that CD133 may has a remarkable role in oral neoplastic transformation $^{[7,8]}$.

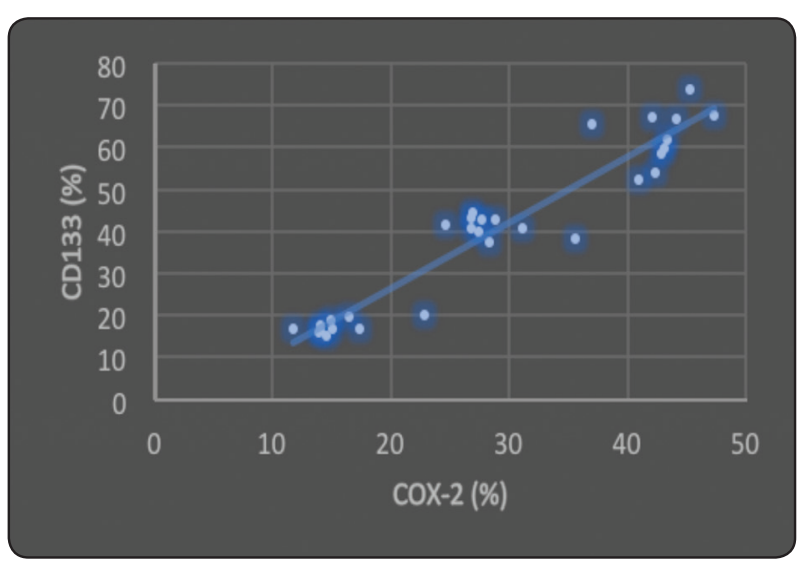

Fig. (3): Scatter diagram representing direct correlation between CD133 and COX-2

Similar to other previous researches, the expression of CD133 in our study was mainly cytoplasmic in all groups, but some dysplastic cells showed other patterns of expression such as membranous and nuclear expression which was in agreement with the expression pattern in gastric adenocarcinoma and hepatocarcinoma ${ }^{[14,27,28]}$.

It has been claimed that the cytoplasmic expression was undoubtedly linked to cancer development and metastasis occurrence and this cytoplasmic expression was considered as an independent prognostic factor. While the membranous expression has been observed in differentiated gastric carcinoma but no specific correlation was found between CD133 membranous expression and tumor progression ${ }^{[27,29,30]}$. So more investigations is needed to clarify the significance of the memraneous CD133 expression in oral cancer. Extensive CD133 nuclear expression have been associated with favorable prognosis in hepatocellular carcinoma cases other than cytoplasmic expression ${ }^{[29]}$. It is recognized that the function of some cellular proteins differs according to their site in the cells and CD133 may be one of these proteins ${ }^{[27]}$.

It is mentioned that CD133 overexpression stimulates the Wnt/b-catenin pathway, which in 
turn leads to neoplastic growth due to increased stemness. The stem cell proliferation affects the growth of the adult cells, which result in the increased tumour size. The activation of Wnt signalling pathway also results in overexpression of VEGF-A and interleukin-8 (IL-8) which leads to stimulation of angiogenesis. However, because of the leaky nature of neoplastic vessels the hypoxia increases with overproduction of reactive oxygen species (ROS) which invigorates the (NF-kb) pathway with the subsequent stimulation of the epithelial-mesenchymal transition (EMT). It has been reported also that $\mathrm{CD} 133$ prevents apoptosis and activates FLIP leading to cytotoxic drugs resistance $^{[31-34]}$.

The present study revealed stromal expression of CD133 in accordance to Margaritescu et al, 2001, results and these positively stained stromal cells could represent a mesenchymal adult stem cells that might participate in cancer development and progression through the stimulation of the tumor associated stroma ${ }^{[35]}$.

On the other hand, COX-2 is a one of molecular markers that correlates with malignant transformation, as several studies concluding it as early event in oral carcinogenesis ${ }^{[36-41]}$.

In the present work, immunohistochemical study of COX-2 protein shown immunonegativity in all of the five cases of normal mucosa which is in consistence with the functional character of this isotype of COX family, where it is considered as an inducible protein mediating many of the inflammatory and carcinogenic processes in the tissues ${ }^{[42]}$. COX-2 immunonegativity in normal oral mucosa was a finding of many other investigators ${ }^{[36-40,43]}$.

At the same time, all cases of oral epithelial dysplasias studied in this work showed positive COX-2 immunoreactivity. However, the extension and the intensity of the reaction were found to increase steadily as the grade of epithelial dysplasia amplified and this gradual increase was statistically significant which was in accordance with many previous studies that guaranteed the gradual increase in the intensity of COX-2 expression among the dysplasia gradient ${ }^{[36-40]}$.

The study of Gitta et al ${ }^{[44]}$ could help the explanation of the basal immunolocalization of COX-2 that was observed in this study. They demonstrated a causative co-relation between the COX-2 overproduction in basal cells and the occurrence of both epithelial hyperplasia and dysplasia. They concluded that COX-2 overproduction appeared to allow epithelial cells proliferation by inhibiting their ingress in the post mitotic stage, which normally is combined with stimulating the expression of the differentiationrelated proteins. Upon overexpression of COX2 , the interaction of the cell with the surrounding cells and matrix components, which is essential for epithelial differentiation as well as keratinocyte polarity, thought to become disturbed.

Another research by Geun et al ${ }^{[45]}$ correlated between COX-2 immunopositivity in the basal cell layer of squamous cell carcinoma and epithelial mesenchymal transition through an increase in Slug (a member of the Snail family that plays an important role in embryonic development) and a decrease in E-cadherin.

The gradual increase in COX-2 immuno expression amongst the layers of the dysplastic epithelium as the grade of the epithelial dysplasia increased, was a finding that was confirmed by the quantitative analysis of the area fraction of COX-2 immunopositive cells among the dysplasia gradient in this study.

The observation of the subcellular localization of COX-2 reaction among the different grades of oral epithelial dysplasia in the present work revealed a combination of cytoplasmic, perinuclear and nuclear reactions. The perinuclear accentuation of the COX-2 immunoexpression noticed in some cells in this study could be explained by the location of this protein in the nuclear envelope and inside 
the lumen of the endoplasmic reticulum, where the oxidizing climate support its appropriate dimerization ${ }^{[46]}$. The nuclear expression of COX2 is harmonious with its role in mitogenesis. The existence of nuclear receptors, thats mediate some of the mitogenic effects of COX-2-derived PGs, confirms the functional link of COX-2 nuclear $\operatorname{expression}^{[47]}$.

On the other hand, the cytoplasmic localization of COX-2 observed in this work may be a direct consequence of proved identification of $\mathrm{COX}-2$ protein inside the cytoplasmic lipid bodies, which seriously impacts tumor proliferation, by acting as an extra origin for the constant supply of $\mathrm{PGs}^{[48]}$. Also, the subcellular localization of COX-2 in the mitochondria of the tumor cells was relied to the protective role played by COX-2 against apoptosis that induced by oxidative stress ${ }^{[49]}$.

In accordance to previous studies ${ }^{[36-39,41,44,51]}$, our study revealed that the stromal cells showed a variable degree of $\mathrm{COX}-2$ immunoreactivity together with the epithelial cells, thus, contributing to overall up-regulation of COX-2 expression in the lesion microenvironment. This was relied to the proved role of COX-2 in carcinogenesis via angiogenesis ${ }^{[45-49]}$ and immunosuppression by IL-10 induction $^{[52]}$.

The present study also showed a statistically significant direct positive correlation between the expression of CD133 and COX-2. This result is in accordance with Jeong Y. et al, 2018, study which clarified a significant strong interrelation between inflammation and the CSC in breast neoplasms. Similarly, Blaylock R., 2015, ${ }^{[53]}$ mentioned that inflammation has a direct influence on stem cell DNA. Shigdar S. et al, 2014, ${ }^{[54]}$ explained that cytokines of inflammatory response allow malignant cells to turn into CSCs through different signalling pathways.

Another explanation for the correlation between the expression of COX-2 and CD133 observed in this study could be related to the role of NF- $x \mathrm{~B}$ pathway.
Activation of NF- $x \mathrm{~B}$ promotes the production of mediators of the epithelial-mesenchymal transition (EMT) in malignant cells, so creating a CSC features [55-57]. At the same time, prostaglandin E(2) strongly shares with tumor necrosis factor-alpha to allow NF-kappaB-dependent gene activation ${ }^{[58,59]}$.

Also CSCs shows an increased level of inflammatory genes due to elevated NF- $x \mathrm{~B}$ stimulation ${ }^{[60]}$. This inter-action between inflammation and stem cells could increase these two properties of tumor cells to further extend the CSC population ${ }^{[61]}$.

In addition, PGE2 has been related to the "phoenix rising pathway," in which tissue destruction starts a repair process. Many of chemotherapeutic drugs act by stimulation of apoptosis. It was reported that apoptotic cells could produce PGE2, that can activate the proliferation of CSCs, allowing more neoplastic cells growth and patient rebound ${ }^{[62]}$.

The growth of malignant stem cells in a spheroid colonies in the culture media indicates its continuous proliferation. The cells which express high COX-2 levels show more spherical pattern which emphasize the interaction between inflammation and stem cells characters ${ }^{[63,64]}$.

Thus, the results of this study suggested that COX2 not only share in malignant tumors development but also in controlling the stem cell proliferation in oral epithelial dysplasia and that there is a bidirectional interplay between inflammation and stemness in oral epithelia dysplasia. The presence of CSCs has a vital role in tumor resistance to cytotoxic drugs. Thus drugs that control the cyclooxygenase-2 expression might restrain stem cells growth and become a new anticancer strategy. ${ }^{[65]}$.

\section{CONCLUSION}

The gradual over expression of CD133 and COX-2 from normal to different grades of oral dysplastic lesions suggests the potential role of these both proteins in oral carcinogenesis. On the other hand, the positive correlation between CD133 and COX-2 in oral dysplastic lesions suggests that 
they might have functional link in oral malignant transformation and might help in the diagnosis and the prediction of the oral cancer development.

\section{RECOMMENDATIONS}

Future investigations is needed to study the correlation between inflammation and stem cell markers expression and actual development of oral squamous cell carcinoma. More investigations are needed to explore the relation between the role and the localization of CD133 in oral dysplastic cells.

\section{REFERENCES}

1- Clarke M., Dick J., Dirks P., Eaves C., Jamieson C., Jones D., Visvader J., Weissman I. and Wahl G.: Cancer stem cells-perspectives on current status and future directions: AACR workshop on cancer stem cells. Cancer Res.; 66: 9339-9344, 2006.

2- Shipitsin M., Campbell L., Argani P., Weremowicz S., Bloushtain-Qimron N., Yao J., Nikolskaya T., Serebryiskaya T., Beroukhim R., Hu M., Halushka M., Sukumar S., Parker L., Anderson K., Harris L., Garber J., Richardson A., Schnitt S., Nikolsky Y., Gelman R. and Polyak K.: Molecular definition of breast tumor heterogeneity. Cancer Cell.; 11: 259-73, 2007.

3- Kelly P., Dakic A., Adams J., Nutt S. and Strasser A.: Tumor growth need not be driven by rare cancer stem cells. Science.; 317: 337, 2007.

4- Chen L., Shen R., Ye Y., Pu X., Liu X., Duan W., Wen J., Zimmerer J., Wang Y., Liu Y., Lasky L., Heerema N., Perrotti D., Ozato K., Kuramochi-Miyagawa S., Nakano T., Yates A., Carson Iii W., Lin H, Barsky S. and Gao JX.: Precancerous stem cells have the potential for both benign and malignant differentiation. PLoS ONE.; 2: e293, 2007.

5- Jian-Xin G.: Cancer stem cells: the lessons from precancerous stem cells. J Cell Mol Med.;12: 67-96, 2008.

6- Kim W. and Ryu C.: Cancer stem cell surface markers on normal stem cells. BMB Rep; 50: 285-298, 2017.

7- Ravindran G. and Devaraj H.: Aberrant expression of CD133 and musashi-1 in preneoplastic and neoplastic human oral squamous epithelium and their correlation with clinicopathological factors. Head Neck; 34: 1129$1135,2012$.
8- Chiou S., Yu C., Huang C., Lin S., Liu C., Tsai T ., Chou S., Chien C., Ku H., Lo J.: Positive correlations of Oct-4 and Nanog in oral cancer stem-like cells and high-grade oral squamous cell carcinoma. Clin Cancer Res;14: 4085 4095, 2008.

9- Maeda S., Shinchi H., Kurahara H., Mataki Y., Maemura K., Sato M., Natsugoe S., Aikou T. and Takao, S.: CD133 expression is correlated with lymph node metastasis and vascular endothelial growth factor-C expression in pancreatic cancer. Br J Cancer; 98: 1389-1397, 2008.

10- Woo T., Okudela K., Mitsui H., Woo T., Okudela K., Mitsui H., Yazawa T., Ogawa N., Tajiri M., Yamamoto T., Rino Y., Kitamura H. and Masuda.: Prognostic value of CD133 expression in stage I lung adenocarcinomas. Int J Clin Exp Pathol; 4: 32-42, 2011.

11- Zhang M., Song T., Yang L., Chen R. Wu L., Yang Z. and Fang J.: Nestin and CD133: valuable stem cells specific markers for determining clinical outcome of glioma patients. J Exp Clin Cancer Res; 27: 85, 2008.

12- Cheng J., Liu B. and Zhang X.: How powerful is CD133 as a cancer stem cell marker in brain tumors? Cancer Treat Rev; 35: 403-408, 2009.

13- Okamoto A., Chikamatsu K., Sakakura K., Hatsushika K., Takahashi G. and Masuyama K.: Expansion and characterization of cancer stem-like cells in squamous cell carcinoma of the head and neck. Oral Oncol; 45: 633-639, 2009.

14- Kang F., Wang K., Wu M., Wang Z., Zhu Y. and Min R.: Biological characteristics of CD133p subpopulation in tongue squamous cell carcinoma Tca8113 cell line. Hua Xi Kou Qiang Yi Xue Za Zhi; 28: 560-564, 2010.

15- Zhang Q., Shi S., Yen Y., Brown J., Ta J. and Le A.: A subpopulation of CD133(p) cancer stem-like cells characterized in human oral squamous cell carcinoma confer resistance to chemotherapy. Cancer Lett; 289:151$160,2010$.

16- Gandhi J., Khera L., Gaur N., Paul C. and Kaul R.: Role of Modulator of Inflammation Cyclooxygenase-2 in Gamma herpes virus Mediated Tumorigenesis. Front Microbiol; 8: 538, 2017.

17- Sergei I., Florian R., and Michael K.: Immunity, Inflammation and Cancer. Cell; 140: 883- 899, 2010.

18- Chan A., Ogino S. and Fuch C.: Aspirin use and survival after diagnosis of colorectal cancer. JAMA; 302: 649-58, 2009. 
19- Smith W., DeWitt D. and Garavito R.: Cyclooxygenases: structural, cellular, and molecular biology. Annu Rev Biochem; 69: 145-82, 2000.

20- Dannenberg A., Altorki N., Boyle J., Dang C., Howe L., Weksler B. and Subbaramaiah K.: Cyclo-oxygenase 2: a pharmacological target for the prevention of cancer. Lancet Oncol; 2: 544-551, 2001.

21- Leng J., Han C., Demetris A., Michalopoulos G. and Wu T.: Cyclooxygenase- 2 promotes hepatocellular carcinoma cell growth through Akt activation: evidence for Akt inhibition in celecoxib-induced apoptosis. Hepatology; 38: 756-768, 2003

22- Medeiros R., Figueiredo C., Pandolfo P., Duarte F., Prediger R., Passos G. and Calixto J.: The role of TNFalpha signaling pathway on COX-2 upregulation and cognitive decline induced by beta-amyloid peptide. Behav Brain Res; 209: 165-173, 2010.

23- Font-Nieves M., Sans-Fons M., Gorina R., Bonfill-Teixidor E., Salas-Pérdomo A., Márquez-Kisinousky L., Santalucia T., Planas A.: Induction of COX-2 enzyme and downregulation of COX-1 expression by lipopolysaccharide (LPS) control prostaglandin E2 production in astrocytes. $\mathrm{J}$ Biol Chem; 287: 6454-6468, 2012.

24- Wang D. and Dubois R.: Prostaglandins and cancer. Gut; 55:115-22, 2006.

25- Jeong Y., Oh H., Park S. and Bong J.: Association between inflammation and cancer stem cell phenotype in breast cancer. Oncology Letters; 15: 2380-2386, 2018.

26- Tampa M., Mitran M., Mitran C., Mitran C., Sarbu M., Mate C., Nicolae I., Caruntu A., Tocut S., Popa M., Caruntu C. and Georgescu S.: Mediators of Inflammation - A Potential Source of Biomarkers in Oral Squamous Cell Carcinoma. J Immunol Res; 2018: 1-12, 2018.

27- Hashimoto K., Aoyagi K., Isobe T., Kouhuji K. and Shirouzu K.: Expression of CD133 in the cytoplasm is associated with cancer progression and poor prognosis in gastric cancer. Gastric Cancer;17: 97-106, 2014.

28- Yu G., Lin X., Luo R. and Fang W.: Nuclear CD133 expression predicts poor prognosis for hepatocellular carcinoma. Int J Clin Exp Pathol; 11: 2092-2099, 2018.

29- Sasaki A., Kamiyama T., Yokoo H., Nakanishi K., Kubota K., Haga H., Matsushita M. , Ozaki M. , Matsuno Y. and Todo S.: Cytoplasmic expression of CD133 is an important risk factor for overall survival in hepatocellular carcinoma. Oncol Rep; 24: 537-46, 2010.
30- Jao S., Chen S., Lin Y., Chang Y., Lee T., Wu C., Jin J. and Nieh S.: Cytoplasmic CD133 expression is a reliable prognostic indicator of tumor regression after neoadjuvant concurrent chemoradiotherapy in patients with rectal cancer. Ann Surg Oncol; 19: 3432-40, 2012.

31- Wang R., Sun Q., Wang P., Wang P., Liu M., Xiong S., Luo J., Huang H., Du Q., Geller D. and Cheng B.: Notch and $\mathrm{Wnt} / \mathrm{b}$-catenin signaling pathway play important roles in activating liver cancer stem cells. Oncotarget; 7: 5754$5768,2016$.

32- Schomig K., Busch G., Steppich B., Sepp D., Kaufmann J., Stein A., Schömig A., Ott I.: Interleukin-8 is asso- $€$ ciated with circulating CD133p progenitor cells in acute myocardial infarction. Eur Heart J; 27: 1032-1037, 2006.

33- Ronca R, Benkheil M, Mitola S, Styyf S. and Liekens S.: Tumor angiogenesis revisited: regulators and clinical implications. Med Res Rev; 37: 1231-1274, 2017.

34- Schmalz P., Shen M. and Park J.: Treatment resistance mechanisms of malignant glioma tumor stem cells. Cancers (Basel); 3: 621-635, 2011.

35- Mărgăritescu C ., Pirici D., Simionescu C. and Stepan A.: The utility of CD44, CD117 and CD133 in identification of cancer stem cells (CSC) in oral squamous cell carcinomas (OSCC). Rom J Morphol Embryol; 52: 985-93, 2011.

36- Shibata M., Kodani I., Osaki M., Kunio A., Hironobu A., Kazuo R. and Hisao I.: Cyclo-oxygenase 1 and 2 expression in oral mucosa, dysplasia and squamous cell carcinomas and their pathological significance. Oral Oncol.; 41: 304312,2005

37- Sun X., Ma J., Zhang H., Wang X. and Li J.: The expression of cyclooxygenase-2 (COX-2), VEGF in oral squamous cell carcinoma and precancerous lesions and their significance. Shanghai Kou Qiang Yi Xue; 14: 173$176,2005$.

38- Hanan Y., Amany N. and Manal A.: Immunohistochemical expression of cyclooxygenase- $2(\mathrm{COX}-2)$ and vascular endothelial growth factor (VEGF) in oral premalignant lesions and squamous cell carcinoma. Bull. Alex. Fac. Med.; 44: 861- 867, 2008.

39- Zhang S., Du Y., Tao J., Wu Y. and Chen N.: Expression of cytosolic phospholipase A2 and cyclooxygenase 2 and their significance in human oral mucosae, dysplasias and squamous cell carcinomas. ORL.; 70: 242- 248, 2008. 
40- Wirth L., Krane J. and Li Y.: A pilot surrogate endpoint biomarker study of celecoxib in oral premalignant lesions. Cancer Prev. Res.; 1: 339- 348, 2008.

41- Nabil F., Misun C., Susan M., Hyung J., Mourad T., Vassiliki A., Adel K., Fadlo R., Zhuo G. and Dong M.: Role of cyclooxygenase-2 in tumor progression and survival of head and neck squamous cell carcinoma. Cancer Prev. Res.; 2: 823- 829, 2009.

42- Thomas G., Nadiminti H. and Regalado J.: Molecular predictors of clinical outcome in patients with head and neck squamous cell carcinoma. Int. J. Exp. Pathol.; 86: 347- 363, 2005.

43- Kutchera W., Jones D., Matsunami N., Groden J., McIntyre T., Zimmerman G., White R. and Prescott S.: Prostaglandin $\mathrm{H}$ synthase-2 is expressed abnormally in human colon cancer: evidence for a transcriptional effect. Proc. Natl. Acad. Sci.; 93: 4816- 4820, 1996.

44- Gitta N., Gerhard F., Markus H., Friedrich M., and Karin M.: Abnormal differentiation of epidermis in transgenic mice constitutively expressing cyclooxygenase-2 in skin. PNAS; 98: 7629- 7634, 2001.

45- Geun W., Nam Y. and Sung C.: Relation between proinflammatory mediators and epithelial-mesenchymal transition in head and neck squamous cell carcinoma. Exp. Therap. Med.; 1: 885- 891, 2010.

46- Morita I., Schindler M. and Regier M.: Different intracellular locations for prostaglandin endoperoxide $\mathrm{H}$ synthase-1 and -2. J. Biol. Chem.; 270: 10902- 10908, 1995 .

47- Wang D., Wang H., Shi Q., Katkuri S., Walhi W., Desvergne B., Das S., Dey S. and DuBois R.: Prostaglandin E2 promotes colorectal adenoma growth via transactivation of the nuclear peroxisome proliferator-activated receptor delta. Cancer Cell; 6: 285- 295, 2004.

48- Accioly M., Pacheco P., Maya M., Carrossini N., Robbs B., Oliveira S., Kaufmann C., Morgado D., Bozza P. and Viola J.: Lipid bodies are reservoirs of cyclooxygenase-2 and sites of prostaglandin-E2 synthesis in colon cancer cells. Cancer Res.; 68: 1732- 1740, 2008.

49- Liou J., Aleksic N., Chen S., Han T., Shyue S. and Wu $\mathrm{K}$.: Mitochondrial localization of cyclooxygenase-2 and calcium independent phospholipase A2 in human cancer cells: implication in apoptosis resistance. Exp. Cell Res.; 306: 75- 84, 2005.
50- Zimmermann K., Sarbia M., Weber A., Borchard F., Gabbert K. and Schror K.: Cyclooxygenase-2 expression in human esophageal carcinoma. Cancer Res.; 59: 198204, 1999.

51- Silvia M., Jose L., Ramon L., Vanessa M., Augusto A., Manuel V. and Luis A.: Evaluation of COX-2, EGFR, and p53 as biomarkers of non-dysplastic oral leukoplakias. Exp. and Mol. Path.; 89: 197- 203, 2010.

52- Harris R.: Cyclooxygenase-2 (cox-2) and the inflammogenesis of cancer. Subcell Biochem.; 42: 93- 126, 2007.

53- Blaylock R.: Cancer microenvironment, inflammation and cancer stem cells: A hypothesis for a paradigm change and new targets in cancer control. Surg Neurol Int; 6:92, 2015.

54- Shigdar S., Li Y., Bhattacharya S., O’Connor M., Pu C., Lin J., Wang T., Xiang D., Kong L., Wei M., Zhu Y., Zhou S. and Duan W.: Inflammation and cancer stem cells. Cancer Lett.; 345: 271-278, 2014.

55- Korkaya S. and Wicha M.: Regulation of cancer stem cells by cytokine networks: attacking cancer's inflammatory roots. Clinical Cancer Research; 17: 6125- 6129, 2011.

56- Shigdar Y., et al.: Inflammation and cancer stem cells. Cancer Letters; 345: 271- 278, 2014.

57- Zhou J., Liu Y. and Liang X.: Inflammation linking EMT and cancer stem cells. Oral Oncology; 48: 1068- 1075, 2012.

58- Poligone B. and Baldwin A.: Positive and negative regulation of NF-kappaB by COX-2: roles of different prostaglandins. J Biol Chem; 276: 38658- 38664, 2001.

59- Liao K., Xia B., Zhuang Q., Hou M., Zhang Y., Luo B., Qiu Y., Gao Y., Li X., Chen H., Ling W., He C., Huang Y., Lin Y., Lin Z.: Parthenolide inhibits cancer stem-like side population of nasopharyngeal carcinoma cells via suppression of the NF- $x \mathrm{~B} / \mathrm{COX}-2$ pathway. Theranostics; 2015; 5:302-321.

60- Garner M., et al.: Constitutive activation of signal transducer and activator of transcription 3 (STAT3) and nuclear factor $\chi \mathrm{B}$ signaling in glioblastoma cancer stem cells regulates the notch pathway. The Journal of Biological Chemistry; 288: 26167-26176, 2013.

61- Da-Wei Y., Li-Rung H., Ya-Wen C., Chi-Ying F. and TsungHsien C.: Interplay between inflammation and stemness in cancer cells: the role of toll-like receptor signaling. Journal of Immunology Research; Article ID 4368101, 14 pages, 2016. 
62- Liu Q., Yuan W., Tong D., Liu G., Lan W., Zhang D., Xiao H., Zhang Y., Huang Z., Yang J., Zhang J. and Jiang J.: Metformin represses bladder cancer progression by inhibiting stem cell repopulation via COX2/PGE2/STAT3 axis. Oncotarget; 7: 28235-28246, 2016.

63- Wilson H., Huelsmeyer M., Chun R., Young K., Friedrichs K. and Argyle D.: Isolation and characterisation of cancer stem cells from canine osteosarcoma. Vet J.; 175:69-75,2008.

64- Pang L., Hurst E., Argyle D.: Cyclooxygenase-2: A Role in Cancer Stem Cell Survival and Repopulation of Cancer
Cells during Therapy. Stem Cells Int; 2016:2048731, 2016.

65- Chimal R., Espinoza S. and Fuentes P.: A Role for the Inflammatory Mediators Cox-2 and Metalloproteinases in Cancer Stemness. Anticancer Agents Med Chem; 15: 837855,2015 .

66- Thanan R., Murata M., Ma N., et al.: Nuclear localization of COX-2 in relation to the expression of stemness markers in urinary bladder cancer. Mediators Inflamm; 2012:165879, 2012. 